\title{
Single-phase high-entropy alloys - an overview
}

\section{Journal Article}

Author(s):

Kozak, Roksolana; Sologubenko, Alla (D); Steurer, Walter

Publication date:

2015-01

Permanent link:

https://doi.org/10.3929/ethz-b-000164352

Rights / license:

In Copyright - Non-Commercial Use Permitted

Originally published in:

Zeitschrift für Kristallographie 230(1), https://doi.org/10.1515/zkri-2014-1739 


\section{Roksolana Kozak*, Alla Sologubenko and Walter Steurer Single-phase high-entropy alloys - an overview}

\begin{abstract}
The term "high-entropy alloys (HEAs)" first appeared about 10 years ago defining alloys composed of $n=5-13$ principal elements with concentrations of approximately 100/n at.\% each. Since then many equiatomic (or near equiatomic) single- and multi-phase multicomponent alloys were developed, which are reported for a combination of tunable properties: high hardness, strength and ductility, oxidation and wear resistance, magnetism, etc. In our paper, we focus on probably single-phase HEAs (solid solutions) out of all HEAs studied so far, discuss ways of their prediction, mechanical properties. In contrast to classical multielement/multiphase alloys, only single-phase multielement alloys (solid solutions) represent the basic concept underlying HEAs as mixing-entropy stabilized homogenous materials. The literature overview is complemented by own studies demonstrating that the alloys $\mathrm{CrFeCoNi}, \mathrm{CrFeCoNiAl}_{0.3}$ and PdFeCoNi homogenized at 1300 and $1100^{\circ} \mathrm{C}$, respectively, for 1 week are not singlephase HEAs, but a coherent mixture of two solid solutions.
\end{abstract}

Keywords: alloy design; intermetallics; mechanical properties at high temperatures; miscellaneous; solid-solution hardening.

DOI 10.1515/zkri-2014-1739

Received February 21, 2014; accepted September 5, 2014; published online October 9, 2014

\section{Introduction}

Starting from 2002 until now, almost 400 papers have been published where the term "high-entropy alloys (HEAs)" is used (Figure 1), in most cases with the focus on microstructure and mechanical properties. The interest in these alloys has especially increased for the last 5 years. What are HEAs? Originally they have been defined as homogenous

*Corresponding author: Roksolana Kozak, Laboratory of Crystallography, Department of Materials, ETH Zurich, VladimirPrelog-Weg 5, 8093 Zurich, Switzerland,

E-mail: roksolana.kozak@mat.ethz.ch

Alla Sologubenko: Laboratory of Nanotechnology, Department of Materials, ETH Zurich, Vladimir-Prelog-Weg 5, 8093 Zurich, Switzerland

Walter Steurer: Laboratory of Crystallography, Department of Materials, ETH Zurich, Vladimir-Prelog-Weg 5, 8093 Zurich, Switzerland alloys composed of 5-13 major elements with concentrations between 5 and 30 at.\%, and with simple average crystal structures such as $c F 4-\mathrm{Cu}(f c c), c I 2-\mathrm{W}(b c c)$ or $c P 2-\mathrm{CsCl}[1-3]$. Their stability (at high enough temperatures) against phase separation and formation of intermetallic phases was explained by the high mixing entropy, which could be achieved if the number of elements was large enough and the stoichiometry close to equiatomic. This was demonstrated experimentally on a few examples and seemed to open up a wide new area for alloy design. The huge number of possible element combinations would make possible combinations of tunable properties that would be hardly possible in conventional alloys such as high hardness, strength and ductility, oxidation and wear resistance, magnetism, etc. $[4,5]$.

In contrast to the expectations, it was found that most element combinations studied experimentally lead to multiphase alloys, which were labeled "HEAs" subsequently anyway. In these cases the microstructure became an important factor for the properties to be studied in the same way as in conventional alloy design. For the development of functional materials is can be crucial to have homogenous single-phase materials. Therefore, it is of interest to screen all the materials labeled "HEAs" so far, whether or not they may be obtainable as single-phase materials. This is the intention of this paper. As we will see in the following that only a few element combinations can be classified as single-phase HEAs.

\section{Theoretical background}

The formation of a particular solid phase is determined by both thermodynamic and kinetic factors [6]. From the thermodynamic point of view, the phase with the lowest Gibbs free energy at given conditions will be formed if $\Delta G_{m i x}<0$, with $\Delta G_{\text {mix }}=\Delta H_{\text {mix }} T \Delta S_{\text {mix }}$. This is always the case for $\left|\Delta H_{\text {mix }}\right|<T \Delta S_{\text {mix }}$ or $\Delta H_{\text {mix }}<0$. The mixing enthalpy, $\Delta H_{\text {mix }}$, can be seen as a measure of the long-range order of the system, which leads to the formation of intermetallic compounds when $\Delta H_{\text {mix }}<0$ or phase separation if $\Delta H_{\text {mix }}>0$. Nevertheless, in multicomponent systems the configurational mixing entropy $\Delta S_{\text {conf }}$ increases with the number of constituents $n$, since

$$
\Delta S_{\text {conf }}=-R \sum_{i=1}^{n} x_{i} \ln \left(x_{i}\right)
$$




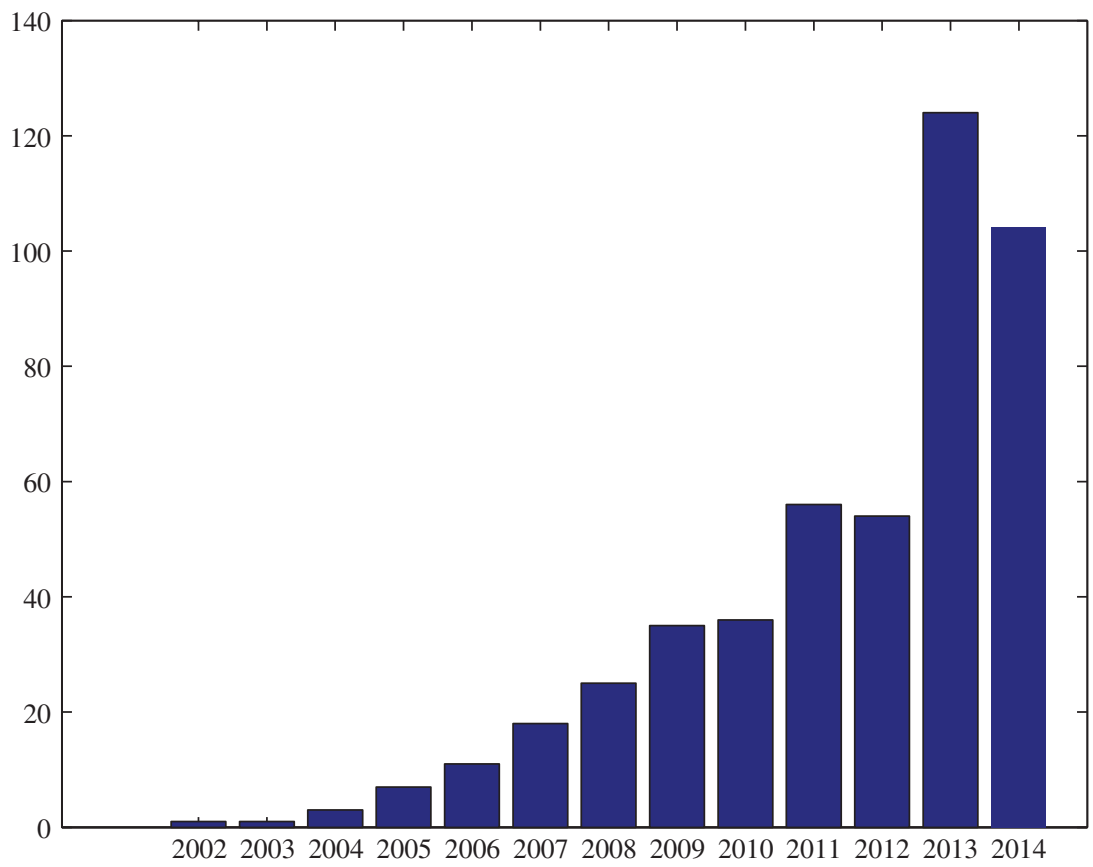

Fig. 1: Publication statistics, giving the number of publications on HEAs per year, for 2014 until July.

( $x$ is the fraction of the $i$-th element), has its maximum value for the equiatomic composition and is a measure of the degree of randomness (disorder) of the system. At sufficiently high temperatures, $\Delta S_{\text {conf }}$ favors the formation of simple solid solutions instead of intermetallic compounds. It should be noted, that the calculation of the configurational entropy of mixing is based on the assumption that each atom is distributed with equal probability, ignoring correlations (short-range order) and interactions between the atoms. Therefore, not only $\Delta S_{\text {conf }}$, but also mixing enthalpy and vibrational entropy can significantly contribute to the phase stability in equiatomic multicomponent alloys [7]. In thermodynamic equilibrium, enthalpy (order) and entropy (disorder) have to compromise providing a minimum of the free energy [8]. In case of single-phase HEAs, the mixing enthalpy is in the range $-15<\Delta H_{\text {mix }}<5 \mathrm{KJ} / \mathrm{mol}$ and $\Delta S_{\text {conf }} \geq 1.61 R$ (for $n=5$ ) [9].

\section{How to "predict" single-phase HEAs?}

Until now, more than 25 possible multicomponent systems have been investigated for the existence of HEAs, based on different combinations of $n=4-9$ elements out of 16 (Figure 2). Two main research families can be identified: I - combinations of light transition metals with $\mathrm{Al}$, and II
- solid solutions of transition metals only (see Figure 2). Their selection and investigation have been done more or less by trial and error [10] since phase diagrams for such multi-component systems are not known. So far, partial vertical cross-sections of phase diagrams have been experimentally studied for the systems $\mathrm{Cr}-\mathrm{Fe}-\mathrm{Co}-\mathrm{Ni}-\mathrm{Al}-\mathrm{Cu}$ [11], Cr-Fe-Co-Ni-Al-Mo [12], Cr-Fe-Co-Ni-Al-Nb [13], and Cr-Fe-Co-Ni-Cu-Ti [14] (note that many authors refer to a mixture of several $f c c$ or $b c c$ and $c P 2-C s C l$ type phases as $f c c$ or bcc solid solutions) and simulated by the CALPHAD method for Cr-Fe-Co-Ni-Al [10], Cr-Fe-Co-Ni-Mn [15], and $\mathrm{Cr}-\mathrm{Nb}-\mathrm{Ti}-\mathrm{V}-\mathrm{Zr}$ [15], which are in agreement with experimental observations of [7, 16], and [17], respectively. Some new single-phase HEAs such as $f c c$ (CoFeMnNi, CuNiPdPt, CuNiPdPtRh) and hcp (CoOsReRu) have been calculated [18]. The accuracy of CALPHAD depends on the completeness of the databases used, i.e., the availability of thermodynamic and kinetic data for all edge (binary, ternary, etc.) phases [19]. In this way, this approach can be used as a basis for the prediction of interactions between the components in multi-component systems; however, disagreements may be observed between the number of phases, their compositions and volume fractions [20]. $\mathrm{Ab}$ initio molecular dynamic simulations for the refractory single-phase HEA TiZrHfNbTa shows the absence of short-range order and segregation in the liquid state that might indicate of formation of single-phase microstructure in solids [18]. 


\begin{tabular}{|c|c|c|c|c|c|c|c|c|c|c|c|c|c|c|c|c|c|}
\hline 1 & 2 & 3 & 4 & 5 & 6 & 7 & 8 & 9 & 10 & 11 & 12 & 13 & 14 & 15 & 16 & 17 & 18 \\
\hline $\begin{array}{c}1 \\
\mathrm{H}\end{array}$ & & & & & & & & & & & & & & & & & $\begin{array}{c}2 \\
\mathrm{He}\end{array}$ \\
\hline 3 & 4 & & & & & & & & & & & 5 & 6 & 7 & 8 & 9 & 10 \\
\hline $\mathrm{Li}$ & $\mathrm{Be}$ & & & & & & & & & & & B & $\mathrm{C}$ & $\mathrm{N}$ & $\mathrm{O}$ & $\mathrm{F}$ & $\mathrm{Ne}$ \\
\hline 11 & 12 & & & & & & & & & & & 13 & 14 & 15 & 16 & 17 & 18 \\
\hline $\mathrm{Na}$ & $\mathrm{Mg}$ & & & & & & & & & & & $\mathrm{Al}$ & $\mathrm{Si}$ & $\mathrm{P}$ & $\mathrm{S}$ & $\mathrm{Cl}$ & $\mathrm{Ar}$ \\
\hline 19 & 20 & 21 & 22 & 23 & 24 & 25 & 26 & 27 & 28 & 29 & 30 & 31 & 32 & 33 & 34 & 35 & 36 \\
\hline $\mathrm{K}$ & $\mathrm{Ca}$ & $\mathrm{Sc}$ & $\mathrm{Ti}$ & $\mathrm{V}$ & $\mathrm{Cr}$ & $\mathrm{Mn}$ & $\mathrm{Fe}$ & Co & $\mathrm{Ni}$ & $\mathrm{Cu}$ & $\mathrm{Zn}$ & $\mathrm{Ga}$ & $\mathrm{Ge}$ & As & $\mathrm{Se}$ & $\mathrm{Br}$ & $\mathrm{Kr}$ \\
\hline 37 & 38 & 39 & 40 & 41 & 42 & 43 & 44 & 45 & 46 & 47 & 48 & 49 & 50 & 51 & 52 & 53 & 54 \\
\hline $\mathrm{Rb}$ & $\mathrm{Sr}$ & Y & $\mathrm{Zr}$ & $\mathrm{Nb}$ & Mo & $\mathrm{Tc}$ & $\mathrm{Ru}$ & $\mathrm{Rh}$ & $\mathrm{Pd}$ & $\mathrm{Ag}$ & $\mathrm{Cd}$ & In & Sn & $\mathrm{Sb}$ & $\mathrm{Te}$ & I & $\mathrm{Xe}$ \\
\hline 55 & 56 & $57 *$ & 72 & 73 & 74 & 75 & 76 & 77 & 78 & 79 & 80 & 81 & 82 & 83 & 84 & 85 & 86 \\
\hline Cs & $\mathrm{Ba}$ & $\mathrm{La}$ & $\mathrm{Hf}$ & $\mathrm{Ta}$ & W & $\operatorname{Re}$ & Os & Ir & $\mathrm{Pt}$ & $\mathrm{Au}$ & $\mathrm{Hg}$ & $\mathrm{Tl}$ & $\mathrm{Pb}$ & $\mathrm{Bi}$ & Po & At & $\mathrm{Rn}$ \\
\hline 87 & 88 & 89 & 104 & & & & & & & & & & & & & & \\
\hline $\mathrm{Fr}$ & $\mathrm{Ra}$ & $\stackrel{+}{\mathrm{Ac}}$ & $\mathrm{Ku}$ & & & & & & & & & & & & & & \\
\hline
\end{tabular}

\begin{tabular}{|c|c|c|c|c|c|c|c|c|c|c|c|c|c|c|}
\hline * Lanthanide & 58 & 59 & 60 & 61 & 62 & 63 & 64 & 65 & 66 & 67 & 68 & 69 & 70 & 71 \\
metals & $\mathrm{Ce}$ & $\mathrm{Pr}$ & $\mathrm{Nd}$ & $\mathrm{Pm}$ & $\mathrm{Sm}$ & $\mathrm{Eu}$ & $\mathrm{Gd}$ & $\mathrm{Tb}$ & $\mathrm{Dy}$ & $\mathrm{Ho}$ & $\mathrm{Er}$ & $\mathrm{Tm}$ & $\mathrm{Yb}$ & $\mathrm{Lu}$ \\
\hline + Actinide & 90 & 91 & 92 & 93 & 94 & 95 & 96 & 97 & 98 & 99 & 100 & 101 & 102 & 103 \\
metals & $\mathrm{Th}$ & $\mathrm{Pa}$ & $\mathrm{U}$ & $\mathrm{Np}$ & $\mathrm{Pu}$ & $\mathrm{Am}$ & $\mathrm{Cm}$ & $\mathrm{Bk}$ & $\mathrm{Cf}$ & $\mathrm{Es}$ & $\mathrm{Fm}$ & $\mathrm{Md}$ & $\mathrm{No}$ & $\mathrm{Lr}$ \\
\hline
\end{tabular}

Fig. 2: Elements involved in the formation of HEAs known so far. For research family I, the respective elements are marked red, for family II - blue (light transition metals) and violet (refractory); some other elements found in alloys claimed to be HEAs are shaded gray.

Out of the more than 100 reported multi-component alloys (Table 1), only a few with approximately equiatomic compositions can be called single-phase solid solutions (at least in the as-cast form): $\mathrm{CrFeCoNi}[21], \mathrm{CrFeCoNiAl}_{0.3}$ [87], CrFeCoNiMn (the first single-phase HEA discovered) [7, 62], $\mathrm{Cr}_{2} \mathrm{Mn}_{27} \mathrm{Fe}_{40} \mathrm{Co}_{5} \mathrm{Ni}_{26}$ [88], $\mathrm{CrFeCoNiMnAl}{ }_{0.2}$ [89], NbMoTaW [79], VNbMoTaW [79] and TiZrHfNbTa [81, 90]. Based on only X-ray powder diffraction (XPD) data, CrFeCoNiPd and $\mathrm{CrFeCoNiPd}_{2}$ [22] are also considered to be single-phase alloys. It should be noted that standard XPD cannot provide information on the phase content of an alloy with accuracy better than $\sim 5 \%$. The formation of intermetallic compounds or of small precipitates at the grain boundaries, as well as inhomogeneities in the composition can be detected only with techniques, such as high-resolution transmission electron microscopy (HRTEM) or 3D atom-probe tomography.

\section{Systems of light transition metals (TM) with Al}

None of the reported equiatomic multicomponent alloys of light transitions metals with $\mathrm{Al}$ are single-phase solid solutions (except foils of $\mathrm{CrFeCoNiAlCu}$ [38] and $\mathrm{CrFeCoNi}$ AlCuTiV [2] synthesized by splat cooling). Their common feature is the eutectic type of interaction between the components. For the systems $\mathrm{CrFeCoNiAl}_{x}[16,23]$ and $\mathrm{CrFeCoNiMnAl}_{x}$ [89] ( $\left.x=0-3\right)$ single-phase HEAs with $c F 4$ $\mathrm{Cu}$ structure type forms with very low $\mathrm{Al}$ content $(x \leq 0.3)$, whereas with high $\mathrm{Al}$ content $(x \geq 1)$, phases with $c I 2-\mathrm{W}$ and $c P 2-\mathrm{CsCl}$ type structures result.

Analyses of the binary phase diagrams of the systems TM-Al show that transition metals, for example Fe, can dissolve up to $\sim 45$ at. $\%$ of $\mathrm{Al}$ at high temperature $\left(1310^{\circ} \mathrm{C}\right)$, whereas the solubility of $T M$ in $\mathrm{Al}$ is negligible $\sim 0$ at.\% [91]. It also should be mentioned that $\mathrm{Al}$ has a larger atomic radius than transition metals and for some of them a lower electronegativity. It easily forms many intermetallic compounds with $T M$ and has a strong tendency towards covalent bonding. According to thermodynamic calculations of binary systems [92] the strongest interaction is between $\mathrm{Ni}$ and $\mathrm{Al}$ which leads to formation of stable compound $\mathrm{NiAl}$ ( $c P 2-\mathrm{CsCl}$ type structure), whereas the weakest between $\mathrm{Cr}$ and $\mathrm{Al}$.

\section{Systems of transition metals only}

In equiatomic light-TM single-phase HEAs (CrFeCoNi, $\mathrm{CrFeCoNiMn),} \mathrm{phases} \mathrm{with} c F 4-\mathrm{Cu}$ type structure have been observed, whereas for refractory metals (NbMoTaW, VNbMoTaW, TiZrHfNbTa) cI2-W type phases result. Although the constituting elements of some of these single-phase HEAs have different structure types at ambient conditions, their high-temperature allotropes (except $\mathrm{Cr}$ ) have the same as the resulting single-phase HEA structure. Consequently, these HEAs are single-phase solid solutions based on the structure type of one element. As data of binary phase diagrams are most comprehensibly 
Tab. 1: First column: nominal composition of the reported single-phase HEAs and multi-phase (a) alloys; second column: sample's treatment (AC - as cast, CR - cold rolled, annealing temperature, if any); third column: average crystal structure type with lattice parameter $a$, if given; fourth column: physical property studied (C - corrosion, E - electrical, M - mechanical, MG - magnetic); fifth column: references (Ref.).

\begin{tabular}{|c|c|c|c|c|}
\hline Nominal composition & Sample's treatment & $\begin{array}{l}\text { Structure } \\
\text { type, } a[\AA]]\end{array}$ & Property & Refs. \\
\hline CrFeCoNi & $\begin{array}{l}\mathrm{CR} \text { to } 350 \mu \mathrm{m}, 1000^{\circ} \mathrm{C}, 1 \mathrm{~h} \\
\text { 1) quenched; } \\
\text { 2) slow cooling to } 480^{\circ} \mathrm{C}, 2 \text { weeks, } \\
\text { slow cooling to room temperature }\end{array}$ & cF4-Cu, - & - & {$[21]$} \\
\hline CrFeCoNi & $A C, C R$ to $100-250 \mu \mathrm{m}$ & cF4-Cu, 3.564 & MG & {$[22]$} \\
\hline CrFeCoNi & $A C$ & $\begin{array}{l}\text { cF4-Cu, } 3.561 \\
\text { cF4-Cu, } 3.587\end{array}$ & $\mathrm{M}, \mathrm{C}$ & {$[23,24]$} \\
\hline CrFeCoNi & $\begin{array}{l}\text { 1) } \mathrm{AC} \\
\text { 2) } 1100^{\circ} \mathrm{C}, 24 \mathrm{~h} \\
\text { 3) } 1100^{\circ} \mathrm{C}, 24 \mathrm{~h} \text { and } \mathrm{CR} \text { to } 50 \% \\
\text { reduction in thickness }\end{array}$ & $\begin{array}{l}\text { cF4-Cu, 3.559, } \\
3.561 \\
3.554\end{array}$ & M & [16] \\
\hline CrFeCoNi & $\mathrm{AC}$ & a & - & {$[25]$} \\
\hline CrFeCoNi & $850^{\circ} \mathrm{C}, 24 \mathrm{~h}$ & a & - & [26] \\
\hline CrFeCoNi & $1200^{\circ} \mathrm{C}, 24 \mathrm{~h}$ & cF4-Cu,- & M & {$[27]$} \\
\hline CrCoNiMn & $1100^{\circ} \mathrm{C}, 24 \mathrm{~h}$ & cF4-Cu,- & M & {$[27]$} \\
\hline FeCoNiMn & $1100^{\circ} \mathrm{C}, 24 \mathrm{~h}$ & cF4-Cu,- & M & {$[27]$} \\
\hline CrFeNiMn & $1100^{\circ} \mathrm{C}, 24 \mathrm{~h}$ & a & M & {$[27]$} \\
\hline CrFeCoMn & $1100^{\circ} \mathrm{C}, 24 \mathrm{~h}$ & a & M & {$[27]$} \\
\hline CrFeCoNiMn & $1200^{\circ} \mathrm{C}, 24 \mathrm{~h}$ & cF4-Cu,- & M & {$[27]$} \\
\hline CrFeCoNiCu & $A C$ & a & - & {$[25]$} \\
\hline $\mathrm{CrFeCoNiTi}_{0.5}$ & $\mathrm{AC}, 600,700,800,1000^{\circ} \mathrm{C}$ & a & M & {$[28]$} \\
\hline CrFeCoNiAl $_{0.25}$ & $\begin{array}{l}\text { 1) } \mathrm{AC} \\
\text { 2) } 1100^{\circ} \mathrm{C}, 24 \mathrm{~h} \\
\text { 3) } 1100^{\circ} \mathrm{C}, 24 \mathrm{~h} \text { and } \mathrm{CR} \text { to } 50 \% \\
\text { reduction in thickness }\end{array}$ & $\begin{array}{l}\text { cF4-Cu, 3.567, } \\
3.576 \\
3.578\end{array}$ & M & [16] \\
\hline $\mathrm{CrFeCoNiAl}_{0.3}$ & $A C$ & cF4-Cu, - & M & {$[23]$} \\
\hline $\mathrm{CrFeCoNiAl}_{0.3}$ & $\begin{array}{l}\text { 1) } \mathrm{AC} \\
\text { 2) } 700^{\circ} \mathrm{C}, 144 \mathrm{~h} \\
\text { 3) } 900^{\circ} \mathrm{C}, 72 \mathrm{~h}\end{array}$ & $\begin{array}{l}\text { cF4-Cu, } 3.60 \\
\text { a }\end{array}$ & M & [29-31] \\
\hline CrFeCoNiAl $_{0.375-2.0}$ & $1100^{\circ} \mathrm{C}, 24 \mathrm{~h}$ & a & M & [16] \\
\hline CrFeCoNiAl $_{1.0}$ & $A C$ & a & - & [32] \\
\hline $\mathrm{CrFeCoNiAl}_{0-3.0} \mathrm{Cu}$ & $A C$ & a & M & [3] \\
\hline $\mathrm{CrFeCoNiAl}_{0.3} \mathrm{Cu}_{0.5}$ & $\begin{array}{l}1100^{\circ} \mathrm{C}, 24 \mathrm{~h} \text {, furnace cooling/ } \\
\text { quenched }\end{array}$ & a/ cF4-Cu, - & - & [33] \\
\hline $\mathrm{CrFeCoNiAl}_{0.5} \mathrm{Cu}_{0.5}$ & $A C$ & a & - & [34] \\
\hline $\mathrm{CrFeCoNiAl}_{0-1.0} \mathrm{Cu}_{0.5}$ & $A C$ & a & - & {$[35]$} \\
\hline $\mathrm{CrFeCoNiAlCu}_{0.5}$ & $A C$ & a & M & {$[36]$} \\
\hline $\mathrm{CrFeCoNiAl}_{1.5-2.0} \mathrm{Cu}_{0.5}$ & $A C$ & a & - & [35] \\
\hline CrFeCoNiAl ${ }_{0.75} \mathrm{Cu}_{0.25}$ & $A C$ & a & - & [34] \\
\hline $\mathrm{CrFeCoNiAlCu}_{0.25}$ & $A C$ & a & - & {$[37]$} \\
\hline $\mathrm{CrFeCoNi}_{0.5} \mathrm{AlCu}$ & $A C$ & a & M & {$[36]$} \\
\hline $\mathrm{CrFeCo}_{0.5} \mathrm{NiAlCu}$ & $A C$ & a & M & [36] \\
\hline $\mathrm{CrFe}_{0.5} \mathrm{CoNiAlCu}$ & $A C$ & a & M & [36] \\
\hline $\mathrm{Cr}_{0.5} \mathrm{FeCoNiAICu}$ & $A C$ & a & M & {$[36]$} \\
\hline CrFeCoNiAlCu & $\mathrm{AC}$ and $600^{\circ} \mathrm{C}, 2 \mathrm{~h} / \mathrm{splat}$ quenched & $\mathrm{a} / \mathrm{CP} 2-\mathrm{CsCl},-$ & MG & {$[38,39]$} \\
\hline $\mathrm{Cr}_{0-2} \mathrm{FeCoNiAlCu}_{0.5}$ & $\mathrm{AC}$ & a & - & [35] \\
\hline $\mathrm{Cr}_{2-3} \mathrm{FeCoNiAl}_{0.5} \mathrm{Cu}_{0.5}$ & $A C$ & a & - & [35] \\
\hline $\mathrm{Cr}_{23}^{2-3} \mathrm{Fe}_{15} \mathrm{Co}_{15} \mathrm{Ni}_{16} \mathrm{Al}_{23} \mathrm{Cu}_{8}$ & $A C$ & a & M & [40] \\
\hline $\mathrm{Cr}_{17} \mathrm{Fe}_{17} \mathrm{Co}_{17} \mathrm{Ni}_{33} \mathrm{Al}_{8} \mathrm{Cu}_{8}$ & $A C$ & a & M & {$[40]$} \\
\hline CrFeCoNiAlCuV $_{0.4-2.0}$ & $A C$ & a & M & [41] \\
\hline CrFeCoNiPd & $A C, C R$ to $100-250 \mu \mathrm{m}$ & cF4-Cu, 3.647 & MG & {$[22]$} \\
\hline $\mathrm{CrFeCoNiPd}_{2}$ & $A C, C R$ to $100-250 \mu \mathrm{m}$ & cF4-Cu, 3.707 & MG & {$[22]$} \\
\hline $\mathrm{CrFeCoNiMo}_{0.3}$ & $\mathrm{AC}$ & a & $M$ & [24] \\
\hline $\mathrm{CrFeCoNiMo}_{03}$ & $A C$ & a & - & [30] \\
\hline
\end{tabular}


(Tab. 1: Continued)

\begin{tabular}{|c|c|c|c|c|}
\hline Nominal composition & Sample's treatment & $\begin{array}{l}\text { Structure } \\
\text { type, } a[\AA]]\end{array}$ & Property & Refs. \\
\hline $\mathrm{CrFeCoNiAl}_{0.3} \mathrm{Mo}_{0.1}$ & $\mathrm{AC} / 700^{\circ} \mathrm{C}, 144 \mathrm{~h}$ & a & - & [29] \\
\hline $\mathrm{CrFeCoNiAlMo}_{0.1}$ & $\mathrm{AC}$ & a & M & {$[42]$} \\
\hline $\mathrm{CrFeCo}_{0.5-2.0} \mathrm{NiAlMo}_{0.5}$ & $\mathrm{AC}$ & a & M & [43] \\
\hline $\mathrm{CrFe}_{0.6-2.0} \mathrm{CoNiAlMo}{ }_{0.5}$ & $\mathrm{AC}$ & a & M & {$[44]$} \\
\hline $\mathrm{Cr}_{0-2.0} \mathrm{FeCoNiAlMo}$ & $A C$ & a & M & [45] \\
\hline $\mathrm{CrFeCoNiAICuMo}_{0.2-1.0}$ & $\mathrm{AC}$ & a & - & [46] \\
\hline CrFeCoNiAlNb $_{0.1}$ & $\mathrm{AC}$ & a & M & [13] \\
\hline $\mathrm{CrFeCO}_{1.5} \mathrm{Ni}_{1.5} \mathrm{Ti}_{0.5}$ & $A C$ & a & $\mathrm{E}$ & {$[47]$} \\
\hline $\mathrm{CrFeCONiTi}_{0.3}$ & $A C$ & a & - & [30] \\
\hline CrFeCoNiTi & $\mathrm{AC} / 1000^{\circ} \mathrm{C}, 2 \mathrm{~h}$ & a & - & {$[48]$} \\
\hline CrFeCoNiTi & $\mathrm{AC}$ & a & M & [49] \\
\hline $\mathrm{CrFeCo}_{1.5} \mathrm{Ni}_{1.5} \mathrm{Ti}_{0.5} \mathrm{Mo}_{0.1-0.8}$ & $A C$ & a & $\mathrm{E}$ & [47] \\
\hline $\mathrm{CrFeCoNiAl}_{0.3} \mathrm{Ti}_{0.1}$ & $\mathrm{AC} / 700^{\circ} \mathrm{C}, 144 \mathrm{~h}$ & a & - & [30] \\
\hline $\mathrm{CrFeCo}_{1.5} \mathrm{Ni}_{1.5} \mathrm{Al}_{0.2}^{0.1} \mathrm{Ti}_{0.5}$ & $1100^{\circ} \mathrm{C}, 4 \mathrm{~h} ; 800^{\circ} \mathrm{C}, 10 \mathrm{~h}$ & a & - & {$[50]$} \\
\hline $\mathrm{CrFeCoNiAl}_{0.5-2.0} \mathrm{Ti}$ & $\mathrm{AC} / 1000^{\circ} \mathrm{C}, 2 \mathrm{~h}$ & a & - & [48] \\
\hline CrFeCoNiAlTi & $A C$ & a & M & {$[51-53]$} \\
\hline $\mathrm{CrFeCO}_{1-3} \mathrm{NiAlTi}_{0.5}$ & $A C$ & a & M & {$[54]$} \\
\hline CrFeCoNiCu & $\mathrm{AC}$ & a & M & {$[2]$} \\
\hline $\mathrm{CrFeCoNiCu}_{0.5-1.0}$ & $A C$ & a & $\mathrm{C}$ & {$[55]$} \\
\hline $\mathrm{CrFeCoNiCu}_{0.5}$ & $\mathrm{AC} / 350-1250^{\circ} \mathrm{C}, 24 \mathrm{~h}$ & a & $\mathrm{C}$ & {$[56]$} \\
\hline CrFeCoNiCuTi $_{0.5}$ & $A C$ & a & M & {$[14,52,57,58]$} \\
\hline CrFeCoNiCuTi $_{0.8-1.0}$ & $A C$ & a & M & [14] \\
\hline CrFeCoNiAl ${ }_{0.25} \mathrm{Cu}_{0.75} \mathrm{Ti}_{0.5}$ & $\mathrm{AC}$ & a & M & {$[57]$} \\
\hline $\mathrm{CrFeCoNiAICu}_{0.25-0.50} \mathrm{Ti}_{0.5}$ & $A C$ & a & M & {$[53]$} \\
\hline $\mathrm{CrFeCoNiAl}_{0.5} \mathrm{CuTi}_{0.2}$ & $\mathrm{AC}$ & a & M & [59] \\
\hline $\mathrm{CrFeCoNiAl}_{0.5} \mathrm{CuTi}_{0.4-2.0}$ & $A C$ & a & M & [59] \\
\hline CrFeCoNiAlCuTi & $A C$ & a & M & {$[60]$} \\
\hline CrFeCoNiAICuTiV & splat-quenched, foil $200 \mu \mathrm{m}$ & $c / 2-W, 2.920$ & M & {$[2]$} \\
\hline$(\mathrm{CrFeCoNiCuTiMnV})_{80} \mathrm{Al}_{20}$ & $A C$ & a & M & {$[61]$} \\
\hline CrFeCoNiMn & $\begin{array}{l}\text { 1) } \mathrm{AC} \\
\text { 2) } 1000^{\circ} \mathrm{C}, 3 \text { days }\end{array}$ & cF4-Cu, 3.59 & - & {$[7,62]$} \\
\hline CrFeCoNiAlCuMn & $A C$ & a & $M$ & {$[60]$} \\
\hline CrFeCoNiAlCuV & $A C$ & a & M & {$[60]$} \\
\hline CrFeCoNiAICuTiV & $A C$ & a & $M$ & {$[2]$} \\
\hline $\mathrm{CrFeNiMo}_{0-0.8} \mathrm{Al}$ & $\mathrm{AC}$ & a & M & {$[63]$} \\
\hline $\mathrm{CrMn}_{2} \mathrm{FeNi}_{2} \mathrm{Cu}$ & $A C$ & a & - & {$[64]$} \\
\hline $\mathrm{CrMnFe}_{1.5} \mathrm{Ni}_{0.5} \mathrm{Al}_{0.5}$ & $\begin{array}{l}\mathrm{AC} / \text { forging at } 1200^{\circ} \mathrm{C} \text { with a } \\
\text { thickness reduction } 50 \% \text {, aged at } \\
1100^{\circ} \mathrm{C} \text { for } 6 \mathrm{~h} \text { followed by air cooling }\end{array}$ & a & $\begin{array}{l}C \\
-\end{array}$ & {$[65,66]$} \\
\hline $\mathrm{CrMnFe}_{1.5} \mathrm{Ni}_{0.5}$ & $A C$ & a & $\mathrm{C}$ & {$[65]$} \\
\hline CrMnFeNiCoNb & $A C$ & a & - & {$[62]$} \\
\hline CrMnFeNiCoGe & $A C$ & a & - & {$[62]$} \\
\hline CrMnFeNiCoCu & $A C$ & a & - & {$[62]$} \\
\hline CrMnFeNiCoTi & $A C$ & a & - & {$[62]$} \\
\hline CrMnFeNiCoV & $\mathrm{AC}$ & a & - & {$[62]$} \\
\hline $\mathrm{CrMnFeNiCu}$ & $\mathrm{AC}$ & a & $M$ & {$[67]$} \\
\hline $\mathrm{Cr}_{2} \mathrm{MnFe}_{2} \mathrm{NiCu}$ & $A C$ & a & - & {$[64]$} \\
\hline $\mathrm{Cr}_{2} \mathrm{Mn}_{2} \mathrm{Fe}_{2} \mathrm{Ni}_{2} \mathrm{Cu}$ & $\mathrm{AC}$ & a & - & [64] \\
\hline $\mathrm{CrMn}_{2} \mathrm{Fe}_{2} \mathrm{NiCu}_{2}$ & $A C$ & a & - & {$[64]$} \\
\hline $\mathrm{CrMnFe}_{2} \mathrm{Ni}_{2} \mathrm{Cu}_{2}$ & $A C$ & a & - & {$[64]$} \\
\hline $\mathrm{Cr}_{2} \mathrm{Mn}_{2} \mathrm{FeNiCu}_{2}$ & $A C$ & a & - & {$[64]$} \\
\hline $\mathrm{Cr}_{2} \mathrm{MnFeNi}_{2} \mathrm{Cu}_{2}$ & $\mathrm{AC}$ & a & - & {$[64]$} \\
\hline $\mathrm{CrMnFe}_{1.5} \mathrm{Ni}_{0.5} \mathrm{Al}_{0.3}$ & $\mathrm{AC}$ & a & $\mathrm{C}$ & {$[65]$} \\
\hline $\mathrm{CrMnFeNiAl}_{0.3-1.0} \mathrm{Cu}$ & $A C$ & a & M & {$[67]$} \\
\hline $\mathrm{MnFeCoTi}_{0.5-2.5} \mathrm{VZr}$ & $A C$ & a & - & {$[68]$} \\
\hline $\mathrm{MnFeCoTiV}_{0.4-3.0} \mathrm{Zr}$ & $A C$ & a & - & {$[68]$} \\
\hline
\end{tabular}


(Tab. 1: Continued)

\begin{tabular}{|c|c|c|c|c|}
\hline Nominal composition & Sample's treatment & $\begin{array}{l}\text { Structure } \\
\text { type, } a[\AA]\end{array}$ & Property & Refs. \\
\hline MnFeCoTiVZr $r_{0.4-3.0}$ & $A C$ & a & - & [68] \\
\hline FeCoNiCuV & $A C$ & a & - & {$[37]$} \\
\hline $\mathrm{FeCoNiCuSn}_{0-0.5}$ & $\mathrm{AC}$ & a & - & [69] \\
\hline $\mathrm{FeCO}_{3} \mathrm{NiAlCu}$ & $\mathrm{AC}$ & a & M & {$[70]$} \\
\hline $\mathrm{FeCo}_{0.2-2} \mathrm{NiAlCu}$ & $A C$ & a & M & {$[70]$} \\
\hline $\mathrm{CrFe}_{1.5} \mathrm{Ni}_{0.5} \mathrm{Al}_{0.2-0.4}$ & $A C$ & a & - & [71] \\
\hline $\mathrm{CrFeNi}_{2} \mathrm{Al}_{0.5} \mathrm{Cu}$ & $\mathrm{AC}, \mathrm{CR}, 500,900,1100^{\circ} \mathrm{C}$ & a & M & {$[72]$} \\
\hline $\mathrm{CrFeNi}_{2} \mathrm{Al}_{1.0-1.2} \mathrm{Cu}$ & $A C$ & a & - & [73] \\
\hline $\mathrm{CrFeNi}_{0.6-1.4} \mathrm{AlCu}$ & $\mathrm{AC}$ & a & M & {$[74]$} \\
\hline CrFeNiAlCu & $\mathrm{AC}$ & a & - & {$[75]$} \\
\hline CrFeNiAlCuTi & $500-1070^{\circ} \mathrm{C}, 4 \mathrm{~h}$ & a & $\mathrm{C}$ & [76] \\
\hline CrFeNiCuMo & $\mathrm{AC}$ & a & - & {$[75]$} \\
\hline CrFeNiCuMn & $A C$ & a & - & {$[75]$} \\
\hline CrFeNiCuZn & $A C$ & a & - & {$[75]$} \\
\hline $\mathrm{CrCoNiAlCu}_{0.5}$ & $A C$ & a & M & {$[2]$} \\
\hline CrCoNiAlCu & $A C$ & a & M & {$[77]$} \\
\hline CrCoNiAlCuAg & $A C$ & a & M & {$[77]$} \\
\hline CrCoNiAICuTiY $_{0-1}$ & $\mathrm{AC}$ & a & M & [78] \\
\hline NbMoTaW & $A C$ & $c / 2-W, 3.2134$ & M & {$[79,80]$} \\
\hline VNbMoTaW & $A C$ & $c / 2-W, 3.1832$ & $M$ & {$[79,80]$} \\
\hline TiZrNbHfTa & $1200^{\circ} \mathrm{C}, 24 \mathrm{~h}$ & c/2-W, 3.404 & $M$ & {$[81,82]$} \\
\hline $\mathrm{TiV}_{0-1} \mathrm{ZrNbMo}$ & $A C$ & a & $M$ & [83] \\
\hline $\mathrm{TiCrZrNbMo} \mathrm{O}_{0.5} \mathrm{Ta}_{0.5}$ & HIP $1450^{\circ} \mathrm{C}, 207 \mathrm{MPa}, 3 \mathrm{~h}$ & a & M & {$[84,85]$} \\
\hline $\mathrm{NbCrMoTiAl}_{0.5}$ & $A C$ & a & & {$[86]$} \\
\hline $\mathrm{NbCrMoVAl}_{0.5}$ & $\mathrm{AC}$ & a & & {$[86]$} \\
\hline $\mathrm{NbCrMoTiVAl}_{0.5}$ & $\mathrm{AC}$ & a & & {$[86]$} \\
\hline
\end{tabular}

available, a guideline based on binary phase diagrams was proposed, which thus can be practically applied to multicomponent alloy systems. According to this approach single-phase solid solutions are assumed in systems, which are characterized by complete solubility or at least have a large solid solution range between their binary pairs [93]. Thermodynamic calculations in [7] and [15] support the conclusion that trends observed in the binary systems are also seen in multicomponent alloys.

Another approach, based on the Bozzolo-FerranteSmith method for alloys, was discussed in [94]. The concept of critical concentrations for each element (limits of solubility) was proposed as an indicator of single-phase HEA formation. For the system V-Nb-Mo-Ta-W it was shown that the transition point to the high-entropy regime was reached for the equiatomic composition in agreement with the experimental observations [80].

The probability of the formation of $f c c$ single-phase HEAs in the systems MnFeCoNiM and MnFeCoNiSm $M$ ( $M$ - an other metallic element) based on a thermodynamic sublattice model and first-principles calculations was examined in [95]. This approach can give an idea whether particular elements prefer to be equally distributed on the Wyckoff positions or have a tendency to occupy only certain sites. However, these theoretical calculations were compared only with a few experimentally studied single-phase HEAs, where the predictive power of this method seems limited.

According to the Hume-Rothery rules, solid solutions can be formed in systems containing elements, whose atomic radii differ by $<\approx 15 \%$ and which have a similar electronegativity (or electron concentration, e/ $a$ ratio). For a visualization of these rules, see, for instance, the Darken-Gurry map [96] of possible solid solutions of other elements in Ta [97]. For single-phase HEAs, these limits are narrower. By analyzing different compositions, the following was proposed as necessary condition:

- atomic size difference $\delta \leq 6.6 \%$ [83], where $\delta=\sqrt{\sum_{i=1}^{n} c_{i}\left(1-\frac{r_{i}}{\bar{r}}\right)^{2}}, \quad c_{i}$ and $r_{i}$ are the concentration and the atomic radius of the $i$-th element, and $\bar{r}$ the average atomic radius, respectively;

- valence electron concentration VEC $\geq 8$ for $f c c$ solid solutions and $\mathrm{VEC}<6.87$ for $b c c$ phases [73], where $\mathrm{VEC}=\sum_{i=1}^{n} c_{i}(\mathrm{VEC})_{i}$ 
- parameter $\Omega \geq 1.1$ [83], defined as $\Omega=\frac{T_{m} \Delta S_{\text {mix }}}{\left|\Delta H_{\text {mix }}\right|}$, with $T_{m}=\sum_{i=1}^{n} c_{i}\left(T_{m}\right)_{i}$ the melting temperature of the $i$-th element, $\Delta S_{\text {mix }}$ and $\Delta H_{\text {mix }}$ the entropy and enthalpy of mixing predicted from Miedema theory [98], respectively.

It should be noted that many multiphase multicomponent alloys also satisfy these criteria.

\section{Crystal structure of single-phase HEAs and the "coloring problem"}

All single-phase HEAs known so far have simple average crystal structures of either the $c F 4-\mathrm{Cu}$ ( $F m \overline{3} m$, [99]), the $c I 2-\mathrm{W}$ ( $\operatorname{Im} \overline{3} m,[100])$ type or its ordered variant $c P 2-\mathrm{CsCl}$ ( $P m \overline{3} m$, [101]). Single-crystalline CrFeCoNi and CrFeCo$\mathrm{NiAl}_{0.3}$ have been already synthesized [87, 93], however, no structural data are available from X-ray single-crystal diffraction experiments. Therefore, many questions are still open: What is the local atomic structure of HEA? How are the different atoms distributed on the lattice? Is there a short-range ordering or clustering? Which correlations are present between atoms? What kinds of clusters are there? All these questions refer to the "coloring problem" of
HEAs [102]. Each element will tend to occupy the position that minimizes its site energy as well as the bond energies, which depend on preferred coordinations, interaction potentials and atomic volumes of the different elements. To experimentally determine the elemental distribution, several complimentary methods have to be applied. Single-crystal diffraction analyses have to be carried out with $\mathrm{X}$-rays and/or neutrons depending on the scattering contrasts of the elements. In addition to the Bragg reflections, which reflect the average structure, the diffuse intensities have to be taken into account as well, in order to get information of the actual local structure. Further information can be obtained from atom probe measurements and electron microscopic investigations.

As it has already been mentioned above, family I of single-phase HEAs contains light transition metals and Al. This element selection resembles that of Heusler phases (a typical representative is $\mathrm{Cu}_{2} \mathrm{MnAl}$ ), which are ordered variants of the $c I 2$-W-type $(2 \times 2 \times 2$ supercells). In Figure 3 , some cI2-W-type derivative structures are illustrated. Locally, in $b c c$ HEAs, related atomic arrangements may be found.

In order to study the variation of local atomic correlations with temperature in refractory single-phase HEA MoNbTaW, a combination of Monte Carlo and molecular dynamics methods has been applied [103]. The simulations show that a phase transition from the disordered $c I 2-\mathrm{W}$ type structure to the ordered $c P 2-\mathrm{CsCl}$ one takes
A

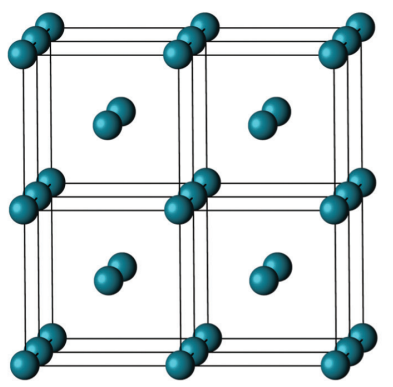

B

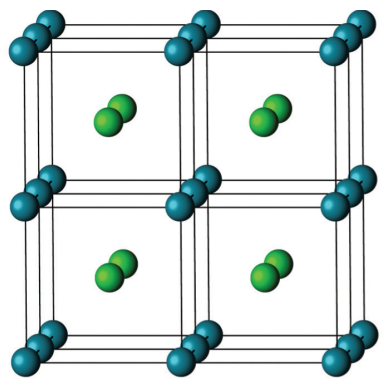

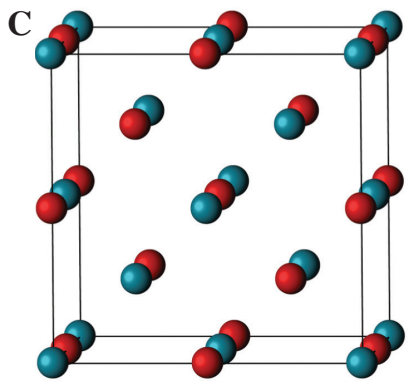
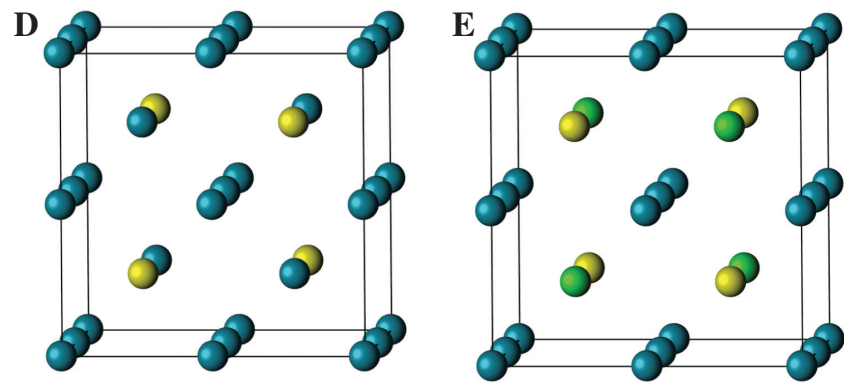

Fig. 3: Schematic representations of some crystal structure types that can be seen as substitutional $2 \times 2 \times 2$ superstructures of the $c / 2$-W type (A): $c P 2-\mathrm{CsCl}(\mathrm{B}), c F 16-\mathrm{NaTl}(\mathrm{C}), c F 16-\mathrm{BiF}_{3}(\mathrm{D})$, and $c F 16-\mathrm{Cu}_{2} \mathrm{MnAl}(\mathrm{E})$. For the $F$ lattices, the origin is shifted by $1 / 4,1 / 4,1 / 4$. 
place between 327 and $527^{\circ} \mathrm{C}$; this is similar to other results [104], whereas favored/disfavored atom pairs in these two works differ.

The electronic structures and basic bulk properties of CrFeCoNi, CrFeCoNiCu, CrFeCoNiCuTi ${ }_{x}$, and CrFeCoNiTi alloys at static conditions ( $0 \mathrm{~K})$, which were assumed to be single-phase paramagnetic random $f c c$ solid solutions, were investigated with DFT calculations using the exact muffin-tin orbitals (EMTO) method in combination with the coherent potential approximation (CPA) in [105]. Calculated and experimental values of atomic volumes for these HEAs are in relatively good agreement, whereas the Young's moduli differ (except for CrFeCoNiTi). A possible reason can be the assumed conditions used in the simulations, as only $\mathrm{CrFeCoNi}$ is a single-phase solid solution according to the experimental observations.

\section{Synthesis and mechanical properties of single-phase HEAs}

Single-phase HEAs can be synthesized like any other conventional alloy $[3,106]$. So far, the samples were prepared in most cases by arc or induction melting [62], splat quenching $[2,39]$ or by the Bridgman technique [87]. It should be noted that some of the alloys were analyzed just in their as-cast state, which conserves the structure of the primary solidified phase, if the kinetics allows. The as-cast phase can undergo phase transformations (ordering, spinodal decomposition/chemical unmixing, precipitation, segregation, nanoparticles formation etc.) during annealing, what can have strong influence on the physical properties of an alloy. In contrast, proper annealing followed by rapid quenching leads to the thermodynamically most stable phase(s) at the annealing temperature.

In most cases, the mechanical properties of singlephase HEAs were investigated by compression, Vickers hardness or tensile tests. The light-TM based single-phase HEAs are less hard (for example, CrFeCoNi 135 HV [24]) than the refractory ones (NbMoTaW $454 \mathrm{HV}$ [79]), but they are more ductile (plastic strain $75 \%$ and engineering strain 7\% for CrFeCoNi and NbMoTaW, respectively).

\section{Solid solution effect}

High hardness and strength of single-phase HEAs are assumed to originate from severe elastic distortions of the crystal lattice caused by the presence of $n$ elements with different atomic sizes. For small amounts of foreign atoms this is called the solid solution strengthening effect. The strengthening originates in the interaction of the strain field around dislocations with the lattice strains, which increase the activation energy for dislocation movement. Differences in chemical interaction and bond strength (covalent contributions) between different elements in the single-phase HEAs can further modify the potential energy surface of a dislocation gliding plane [107]. However, in equiatomic single-phase HEAs, there are no clearly defined solute or solvent atoms. The mechanism of dislocations movement in these "corrugated structures" is unclear [90]. No quantitative models for the description of strengthening by lattice distortions are provided yet.

\section{Influence of thermo-mechanical treatment on mechanical properties of single-phase HEAs}

Single-phase HEAs are potentially very valuable materials, which can have a variety of different tunable properties, depending on the kind and concentration of constituting elements (the so-called 'cocktail effect') [4]. For instance, materials that possess superior mechanical properties at elevated temperatures are in great demand for the aerospace industry. NbMoTaW, VNbMoTaW, and TiZrNbHfTa are examples for HEAs, which possess a high-temperature strength and thermal resistance comparable to superalloys [80, 82]. As it can be seen from Figure 4, the yield strength values for these single-phase HEAs are higher than for Haynes 230 , and at $\mathrm{T}>800^{\circ} \mathrm{C}$ even higher than Inconel 718, with rather weak decrease of yield strength up to $1600^{\circ} \mathrm{C}$. This strong resistance to softening at high temperatures is probably due to the sluggish diffusion [108] through the strained lattices of single-phase HEAs.

Alloys that possess both high strength and ductility are also promising for low-temperature structural applications [109]. From first-principle electronic structure calculations it was shown that the stacking fault energy decreases with increasing number of components in the alloy $\left(\sim 100 \mathrm{~mJ} / \mathrm{m}^{2}\right.$ and $<15 \mathrm{~mJ} / \mathrm{m}^{2}$ for $\mathrm{NiAl}$ and $\mathrm{CrFeCoN}$ iMn, respectively), and approximately on the same order of some conventional austenitic stainless steels $\left(18 \mathrm{~mJ} / \mathrm{m}^{2}\right.$ for AISI 304L). The alloy $\mathrm{Cr}_{26} \mathrm{Fe}_{20} \mathrm{Co}_{20} \mathrm{Ni}_{14} \mathrm{Mn}_{20}$ with optimal value of stacking fault energy $7.7 \mathrm{~mJ} / \mathrm{m}^{2}$ was designed by varying $\mathrm{Ni} / \mathrm{Cr}$ concentration.

It is well known that mechanical properties are very sensitive to the microstructure and therewith to the preparation conditions. For example, annealing temperature and time, cold or hot deformation (rolling), and grain size play an important role [16, 21, 22]. As with other alloys, the 


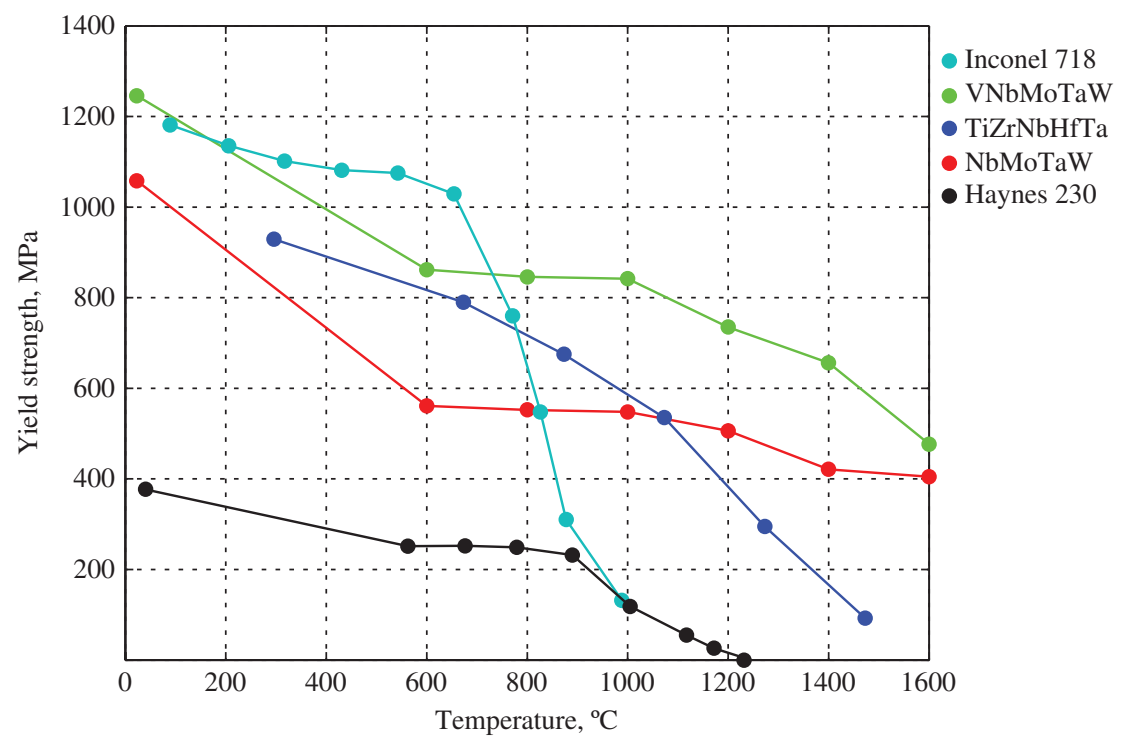

Fig. 4: Yield strength as a function of temperature for refractory HEAs in comparison with the Ni-based superalloys Inconel 718 and Haynes $230[80,82]$.

grain size has a major influence on tensile strength, i.e., the Hall-Petch effect, as it was shown for CrMnFeCoNi [110].

The hardness of $\mathrm{CrFeCoNiAl}_{0.25}$ amounts to $113 \mathrm{HV}$ [16], quite similar to that of the pure metals. After deformation by rolling to $50 \%$ reduction in thickness, its hardness was significantly improved to 325-346 HV. No stress-induced phase transition was observed under rolling. Cold rolling increases the strength of the alloy $\mathrm{Cr}_{2} \mathrm{Mn}_{27} \mathrm{Fe}_{40} \mathrm{Co}_{5} \mathrm{Ni}_{26}$ [88] due to work hardening, whereas it decreases the ductility, what may be explained by a decreasing amount of strain hardening with increasing deformation. The dislocationslip deformation mechanism is proposed for this alloy: with applying higher strains more slip planes are activated and the dislocation density increases; the planar dislocation structure is reorganized into dislocation cells [88].

Tensile tests of single-phase HEAs with compositions $\mathrm{CrFeCoNi}$ and $\mathrm{CrFeCoNiMn}$ over a wide temperature range show an increase in ductility and strength with an decrease in temperature [111]. Closer investigations indicate an increasing importance of the twinning deformation mechanism at lower temperature. This was explained by a more pronounced effect of the thermal activation of the dislocation mobility due to the higher amount of obstacles on the gliding planes, in comparison to alloys with a lower number of alloying elements. On a smaller scale, this effect can already be observed in binary alloys, e.g., $\mathrm{Cu}-\mathrm{Al}, \mathrm{Cu}-\mathrm{Ge}, \mathrm{Cu}-\mathrm{Mn}$ [112-114]. In contrast, it seems that the stacking-fault energy does not change much with temperature, and therefore can be ruled out as the cause for the difference in the deformation mechanism.
The reduction of crystal defects such as dislocations and grain boundaries can improve the strength and ductility of alloys [115]. Indeed, micron- and nanometer-sized pillars of NbMoTaW exhibit higher strength and ductility than the respective bulk materials. The properties of the HEA pillars are better than of the pillars of any of the pure elements. Furthermore, the size effect for the properties resulted smaller for the single-phase HEA than for the pure metals. The better mechanical characteristics are explained by the high amount of local atomic distortion typical for HEAs.

\section{Transmission electron microscopy (TEM) studies of some possible single-phase HEAs}

In order to check experimentally existence of single-phase HEAs in light-transition metal systems the samples with the nominal compositions $\mathrm{CrFeCoNi}$, $\mathrm{CrFeCoNiAl}_{0.3}$, PdFeCoNi and masses of $0.7 \mathrm{~g}$ each were synthesized by arc-melting from powders of pure metals (Cr: 99.996\%, Fe: 99.998\%, Co: 99.995\%, Ni: 99.999\%, Pd: 99.99\% Al: 99.999\%). The weight losses were less than $1 \%$. The prealloys were placed in $\mathrm{Al}_{2} \mathrm{O}_{3}$ crucibles, then closed under $\mathrm{Ar}$ atmosphere in $\mathrm{Ta}$ ampoules and welded. The samples $\mathrm{CrFeCoNi}$, CrFeCo$\mathrm{NiAl}_{0.3}$ were homogenization at $1300^{\circ} \mathrm{C}$ and $\mathrm{PdFeCoNi}$ at $1100^{\circ} \mathrm{C}$ for 1 week and subsequently quenched in water. From X-ray powder diffraction patterns and BSE images 
fcc lattice and single-phase microstructure for the synthesized samples was confirmed. TEM specimens were prepared by the standard mechanical grinding, dimpling and ion milling for perforation (PIPS 2). TEM experiments were performed on FEI Tecnai F30 machine operated at $300 \mathrm{kV}$.

TEM studies of the sample $\mathrm{CrFeCONiAl}_{0.3}$ confirmed its single-crystalline nature and $f c c$ structure from electron diffraction pattern acquired from $800 \mathrm{~nm}$ large areas. On a two beam bright field image acquired close to the [0-11] zone axis with the $\mathrm{g}=111$ as a second strong reflection (Figure 5A), the heterogeneous morphology is observed due to inclusions seen as dark speckles (approximately $20 \mathrm{~nm}$ size or less) homogeneously distributed in the matrix. The same features were observed for the CrFeCoNi alloy. The chemical nature of the speckles was confirmed by HAADF-STEM, an atomic number sensitive imaging technique (Figure 5B), where the speckles look bright upon dark background contrast of the matrix. Most likely it might be concluded that the onset of the phase decomposition has already taken place. The Matrix (bright region) and speckles (dark region) are fully coherent phases with the same structure and very similar unit-cell parameters like it is reported for the binary alloy in the system Cr-Fe [116], and what was found in the as-cast alloy $\mathrm{CrFeCoNiAl} \mathrm{[32].} \mathrm{The} \mathrm{elemental} \mathrm{content} \mathrm{analy-}$ ses of the small particles are not reliable since particles are too small to give a decent signal-to-noise ratio in the STEMEDX line-profile. The compositional variations could be confirmed with 3D atom probe tomography, indicating that the material is not single-phase.

An analysis of the respective binary phase diagrams shows that the phase separation may be caused by the presence of $\mathrm{Cr}$ in the samples. $\mathrm{Cr}$ forms a continuous solid solution with $\mathrm{Fe}$, whereas it can dissolve only up to 30 at.\% of $\mathrm{Ni}$ [91]. Therefore, in another experiment $\mathrm{Cr}$ was replaced by Pd, which forms continuous solid solutions with three other elements $\mathrm{Fe}$, Co, Ni. However, the same heterogeneous morphology was observed as for the sample with $\mathrm{Cr}$ (Figure 6).

\section{Conclusions and open questions}

It is still an open question, how many different single-phase HEAs do exist in thermodynamic equilibrium, and in which compositional and temperature ranges. As it was shown in [7] for the single-phase HEA CrFeCoNiMn, the replacement of just one element at a time in the alloy by a neighboring element from the periodic table (Cr by Mo or V, Fe by V, Co by $\mathrm{Ti}$, $\mathrm{Ni}$ by $\mathrm{Cu}$ ) leads to a multiple-phase microstructure. Is there an optimum (with regard to the size of the compositional and temperature stability range) or maximum number of constituents before phase separation takes place? So far, the maximum number of constituents reported for singlephase HEAs was $n=6$ [89]. What are the ranges of tolerance of the crystal lattice before phase separation takes place? According to the "confusion principle" [117]: the more constituent elements of the alloy, the lower the chance for them to select one out of all possible crystal structures and, therefore, the greater the probability of glass formation followed by phase separation if thermally equilibrated.

The average crystal structures of the so far reported single-phase HEAs belong to one of the three simple types: $c F 4-\mathrm{Cu}, c I 2-\mathrm{W}$ or $c P 2-\mathrm{CsCl}$. Are there any other structure types prone to the formation of HEAs? How are the
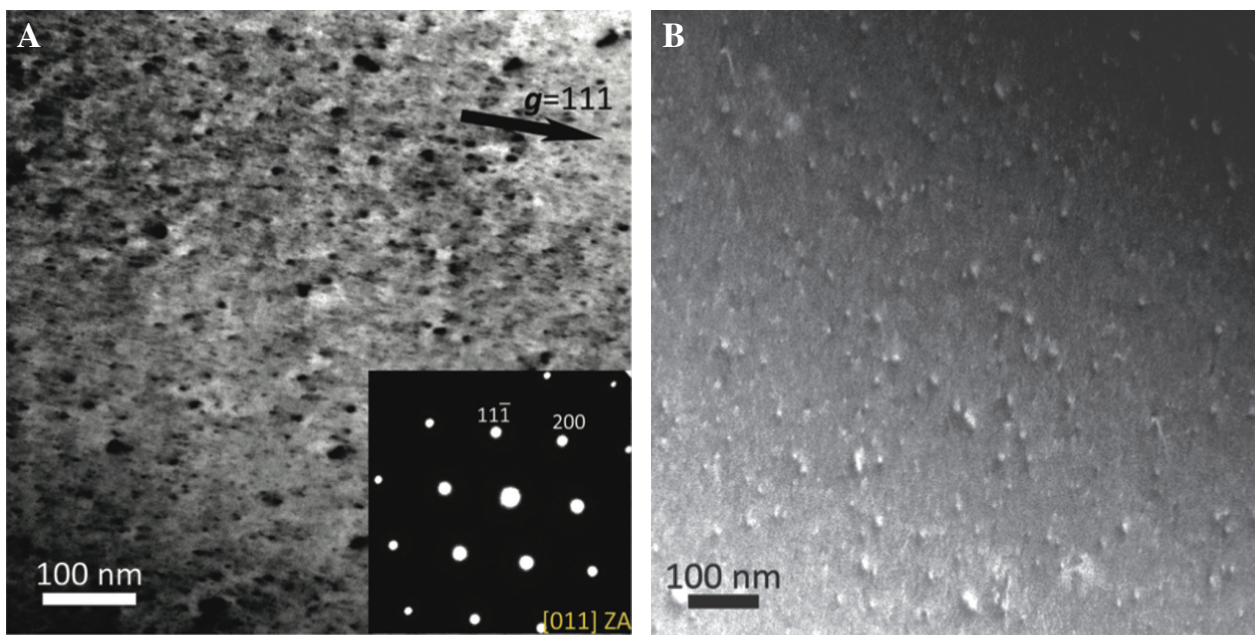

Fig. 5: A - The two beam TEM bright-field image acquired in the orientation close to [0-11] zone axis with the $\mathrm{g}=111$ as an active reflection of the sample $\mathrm{CrFeCoNiAl}_{0.3}\left(1300^{\circ} \mathrm{C}, 1\right.$ week); In the insert is a diffraction pattern from the area in $\mathrm{A}$, acquired in the exact zone axis orientation. B - HAADF STEM image off zone axis of the sample $\mathrm{CrFeCoNiAl}_{0.3}\left(1300^{\circ} \mathrm{C}, 1\right.$ week). 

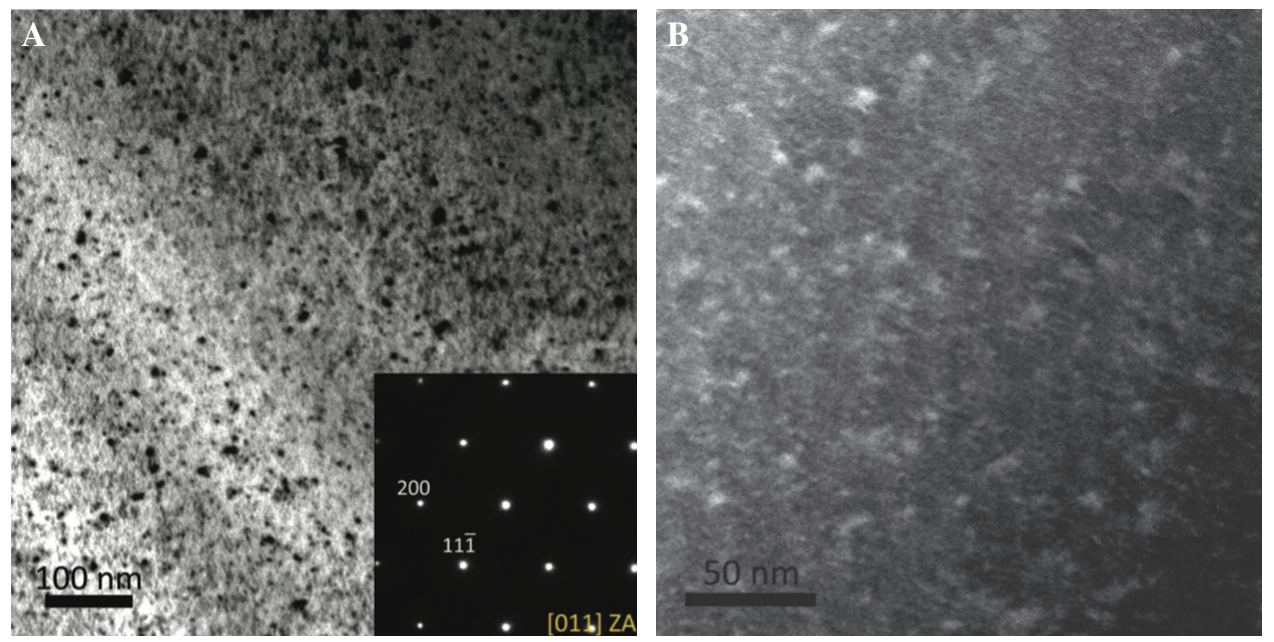

Fig. 6: A - TEM bright-field image with SAD pattern of $f c c$ [011] zone axis of the sample PdFeCoNi $\left(1100^{\circ} \mathrm{C}, 1\right.$ week); B - HAADF STEM image off zone axis of the sample PdFeCoNi $\left(1100^{\circ} \mathrm{C}, 1\right.$ week).

elements distributed on the atomic sites of the structures? Is there any kind of short-range clustering and/or ordering? How distorted are the structures?

Single-phase HEAs have been reported to excel by a variety of properties, especially mechanical ones. What is the origin of special properties such as high hardness in combination with significant ductility? It is essential to understand the kind of short-range order present, if any, in order to control and tune interesting properties directly.

\section{References}

[1] J. W. Yeh, High-entropy multi-elements alloys, Patent US2002/0159914A1.

[2] J. W. Yeh, S. K. Chen, J. Y. Gan, S. J. Lin, T. S. Chin, T. T. Shun, C. H. Tsau, S. Y. Chang, Formation of simple crystal structures in Cu-Co-Ni-Cr-Al-Fe-Ti-V alloys with multiprincipal metallic elements. Metall. Mater. Trans. A 2004, 35, 2533.

[3] J. W. Yeh, S. K. Chen, S. J. Lin, J. Y. Gan, T. S. Chin, T. T. Shun, C. H. Tsau, S. Y. Chang, Nanostructured high-entropy alloys with multiple principal elements: novel alloy design concepts and outcomes. Adv. Eng. Mater. 2004, 6, 299.

[4] J. W. Yeh, Recent progress in high-entropy alloys. Ann. Chim. Sci. Mat. 2006, 31, 633.

[5] Y. Zhang, T. T. Zuo, Z. Tang, M. C. Gao, K. A. Dahmen, P. K. Liaw, Z. P. Lu, Microstructures and properties of high-entropy alloys. Prog. Mater. Sci. 2014, 61, 1.

[6] D. A. Porter, K. E. Easterling, Phase Transformations in Metals and Alloys,2nd ed., CRC Press, Boca Raton, 2004.

[7] F. Otto, Y. Yang, H. Bei, E. P. George, Relative effects of enthalpy and entropy on the phase stability of equiatomic high-entropy alloys. Acta Mater. 2013, 61, 2628.

[8] I. Muller, Entropy and energy, - a universal competition. Entropy 2008, 10, 462.
[9] Y. Zhang, Y. Zhou, Solid solution formation criteria for high entropy alloys. Mater. Sci. Forum 2007, 561-565, 1337.

[10] C. Zhang, F. Zhang, S. L. Chen, W. S. Cao, Computational thermodynamics aided high-entropy alloy design. J. Miner. Met. Mater. Soc. 2012, 64, 839.

[11] C. J. Tong, Y. L. Chen, S. K. Chen, J. W. Yeh, T. T. Shun, C. H. Tsau, S. J. Lin, S. Y. Chang, Microstructure characterization of $\mathrm{Al}_{\mathrm{x}} \mathrm{CoCrCuFeNi}$ high-entropy alloy system with multiprincipal elements. Metall. Mater. Trans. A 2005, 36, 881.

[12] C. Y. Hsu, C. C. Juan, S. T. Chen, T. S. Sheu, J. W. Yeh, S. K. Chen, Phase diagrams of high-entropy alloy system Al-Co-Cr-Fe-MoNi. JOM 2013, 65, 1848.

[13] S. G. Ma, Y. Zhang, Effect of Nb addition on the microstructure and properties of AlCoCrFeNi high-entropy alloy. Mater. Sci. Eng. A 2012, 532, 480.

[14] X. F. Wang, Y. Zhang, Y. Qiao, G. L. Chen, Novel microstructure and properties of multicomponent $\mathrm{CoCrCuFeNiTi}_{\mathrm{x}}$ alloys. Intermetallics 2007, 15, 357.

[15] F. Zhang, C. Zhang, S. L. Chen, J. Zhu, W. S. Cao, U. R. Kattner, An understanding of high entropy alloys from phase diagram calculations. Calphad 2014, 45, 1.

[16] Y. F. Kao, T. J. Chen, S. K. Chen, J. W. Yeh, Microstructure and mechanical property of as-cast, -homogenized, and -deformed $\mathrm{Al}_{\mathrm{x}} \mathrm{CoCrFeNi}(0 \leq \mathrm{x} \leq 2)$ high-entropy alloys. J. Alloys Compd. 2009, 488, 57.

[17] O. N. Senkov, S. V. Senkova, C. Woodward, D. B. Miracle, Lowdensity, refractory multi-principal element alloys of the $\mathrm{Cr}-\mathrm{Nb}$ Ti-V-Zr system: microstructure and phase analysis. Acta Mater. 2013, 61, 1545.

[18] M. C. Gao, D. E. Alman, Searching for next single-phase highentropy alloy compositions. Entropy 2013, 15, 4504.

[19] G. Bozzolo, R. D. Noebe, P. B. Abel, Applied Computational Materials Modeling: Theory, Simulation and Experiment, Springer, New York, p. 502, 2007.

[20] O. Senkov, F. Zhang, J. Miller, Phase composition of a $\mathrm{CrMo}_{0.5} \mathrm{NbTa}_{0.5} \mathrm{TiZr}$ high entropy alloy: comparison of experimental and simulated data. Entropy 2013, 15, 3796.

[21] M. S. Lucas, G. B. Wilks, L. Mauger, J. A. Munoz, O. N. Senkov, E. Michel, J. Horwath, S. L. Semiatin, M. B. Stone, D. L. 
Abernathy, E. Karapetrova, Absence of long-range chemical ordering in equimolar FeCoCrNi. Appl. Phys. Lett. 2012, 100, 251907.

[22] M. S. Lucas, L. Mauger, J. A. Munoz, Y. M. Xiao, A. O. Sheets, S. L. Semiatin, J. Horwath, Z. Turgut, Magnetic and vibrational properties of high-entropy alloys. J. Appl. Phys. 2011, 109, 07 E307.

[23] W. R. Wang, W. L. Wang, S. C. Wang, Y. C. Tsai, C. H. Lai, J. W. Yeh, Effects of Al addition on the microstructure and mechanical property of $\mathrm{Al}_{\mathrm{x}} \mathrm{CoCrFeNi}$ high-entropy alloys. Intermetallics 2012, 26, 44.

[24] T. T. Shun, L. Y. Chang, M. H. Shiu, Microstructure and mechanical properties of multiprincipal component $\mathrm{CoCrFeNiMo(x)}$ alloys. Mater. Charact. 2012, 70, 63.

[25] S. Guo, C. Ng, Z. Wang, C. T. Liu, Solid solutioning in equiatomic alloys: limit set by topological instability. J. Alloys Compd. 2014, 583, 410.

[26] A. K. Singh, A. Subramaniam, On the formation of disordered solid solutions in multi-component alloys. J. Alloys Compd. 2014, 587, 113.

[27] Z. Wu, H. Bei, F. Otto, G. M. Pharr, E. P. George, Recovery, recrystallization, grain growth and phase stability of a family of FCC-structured multi-component equiatomic solid solution alloys. Intermetallics 2014, 46, 131.

[28] L. Jiang, Y. Lu, Y. Dong, T. Wang, Z. Cao, T. Li, Annealing effects on the microstructure and properties of bulk high-entropy CoCrFeNiTi 0.5 alloy casting ingot. Intermetallics 2014, 44, 37.

[29] T. T. Shun, Y. C. Du, Microstructure and tensile behaviors of FCC $\mathrm{Al}_{0.3} \mathrm{CoCrFeNi}$ high entropy alloy. J. Alloys Compd. 2009, 479, 157.

[30] T. T. Shun, C. H. Hung, C. F. Lee, Formation of ordered/disordered nanoparticles in FCC high entropy alloys. J. Alloys Compd. 2010, 493, 105.

[31] T. T. Shun, C. H. Hung, C. F. Lee, The effects of secondary elemental $\mathrm{Mo}$ or $\mathrm{Ti}$ addition in $\mathrm{Al}_{0.3} \mathrm{CoCrFeNi}$ high-entropy alloy on age hardening at 700 degrees C. J. Alloys Compd. 2010, 495, 55.

[32] A. Manzoni, H. Daoud, R. Volkl, U. Glatzel, N. Wanderka, Phase separation in equiatomic AlCoCrFeNi high-entropy alloy. Ultramicroscopy 2013, 132, 212.

[33] M. H. Tsai, H. Yuan, Morphology, structure and composition of precipitates in $\mathrm{Al}_{0.3} \mathrm{CoCrCu}_{0.5} \mathrm{FeNi}$ high-entropy alloy. Intermetallics 2013, 32, 329.

[34] Y. J. Zhou, Y. Zhang, F. J. Wang, G. L. Chen, Phase transformation induced by lattice distortion in multiprincipal component CoCrFeNiCu $\mathrm{Al}_{1-\mathrm{x}}$ solid-solution alloys. Appl. Phys. Lett. 2008, 92, 241917.

[35] G.Y. Ke, S. K. Chen, T. Hsu, J. W. Yeh, FCC and BCC equivalents in as-cast solid solutions of $\mathrm{Al}_{\mathrm{x}} \mathrm{Co}_{\mathrm{y}} \mathrm{Cr}_{\mathrm{z}} \mathrm{Cu}_{0.5} \mathrm{Fe}_{\mathrm{v}} \mathrm{Ni}_{\mathrm{w}}$ high-entropy alloys. Ann. Chim. Sci. Mat. 2006, 31, 669.

[36] C. C. Tung, J. W. Yeh, T. T. Shun, S. K. Chen, Y. S. Huang, H. C. Chen, On the elemental effect of AlCoCrCuFeNi high-entropy alloy system. Mater. Lett. 2007, 61, 1.

[37] Y. Zhang, Y. J. Zhou, J. P. Lin, G. L. Chen, P. K. Liaw, Solid-solution phase formation rules for multi-component alloys. Adv. Eng. Mater. 2008, 10, 534.

[38] S. Singh, N. Wanderka, B. S. Murty, U. Glatzel, J. Banhart, Decomposition in multi-component AlCoCrCuFeNi high-entropy alloy. Acta Mater. 2011, 59, 182.

[39] S. Singh, N. Wanderka, K. Kiefer, K. Siemensmeyer, J. Banhart, Effect of decomposition of the $\mathrm{Cr}$-Fe-Co rich phase of $\mathrm{AlCoCr}$ -
CuFeNi high entropy alloy on magnetic properties. Ultramicroscopy 2011, 111, 619.

[40] A. Manzoni, H. Daoud, S. Mondal, S. van Smaalen, R. Völkl, U. Glatzel, N. Wanderka, Investigation of phases in $\mathrm{Al}_{23} \mathrm{Co}_{15} \mathrm{Cr}_{23} \mathrm{Cu}_{8} \mathrm{Fe}_{15} \mathrm{Ni}_{16}$ and $\mathrm{Al}_{8} \mathrm{Co}_{17} \mathrm{Cr}_{17} \mathrm{Cu}_{8} \mathrm{Fe}_{17} \mathrm{Ni}_{33}$ high entropy alloys and comparison with equilibrium phases predicted by Thermo-Calc. J. Alloys Compd. 2013, 552, 430.

[41] M. R. Chen, S. J. Lin, J. W. Yeh, S. K. Chen, Y. S. Huang, M. H. Chuang, Effect of vanadium addition on the microstructure, hardness, and wear resistance of $\mathrm{Al}_{0.5} \mathrm{CoCrCuFeNi} \mathrm{high-}$ entropy alloy. Metall. Mater. Trans. A 2006, 37A, 1363.

[42] J. M. Zhu, H. M. Fu, H. F. Zhang, A. M. Wang, H. Li, Z. Q. Hu, Microstructures and compressive properties of multicomponent AlCoCrFeNiMox alloys. Mater. Sci. Eng. A 2010, 527, 6975.

[43] C. Y. Hsu, W. R. Wang, W. Y. Tang, S. K. Chen, J. W. Yeh, Microstructure and mechanical properties of new $\mathrm{AlCo}_{\mathrm{x}} \mathrm{CrFeMo}_{0.5} \mathrm{Ni}$ high-entropy alloys. Adv. Eng. Mater. 2010, 12, 44.

[44] C. Y. Hsu, T. S. Sheu, J. W. Yeh, S. K. Chen, Effect of iron content on wear behavior of $\mathrm{AlCoCrFe}_{x} \mathrm{Mo}_{0.5} \mathrm{Ni}$ high-entropy alloys. Wear 2010, 268, 653.

[45] C. Y. Hsu, C. C. Juan, W. R. Wang, T. S. Sheu, J. W. Yeh, S. K. Chen, On the superior hot hardness and softening resistance of $\mathrm{AlCoCr}_{\mathrm{x}} \mathrm{FeMo}_{0.5} \mathrm{Ni}$ high-entropy alloys. Mater. Sci. Eng. A 2011, 528, 3581.

[46] J. M. Zhu, H. F. Zhang, H. M. Fu, A. M. Wang, H. Li, Z. Q. Hu, Microstructures and compressive properties of multicomponent AlCoCrCuFeNiMo alloys. J. Alloys Compd. 2010, 497, 52.

[47] Y. L. Chou, J. W. Yeh, H. C. Shih, The effect of molybdenum on the corrosion behaviour of the high-entropy alloys $\mathrm{Co}_{1.5} \mathrm{CrFeNi}_{1.5} \mathrm{Ti}_{0.5} \mathrm{Mo}_{\mathrm{x}}$ in aqueous environments. Corros. Sci. 2010, 52, 2571.

[48] K. B. Zhang, Z. Y. Fu, Effects of annealing treatment on phase composition and microstructure of $\mathrm{CoCrFeNiTiAl}_{x}$ high-entropy alloys. Intermetallics 2012, 22, 24.

[49] K. B. Zhang, Z. Y. Fu, J. Y. Zhang, W. M. Wang, H. Wang, Y. C. Wang, Q. J. Zhang, J. Shi, Microstructure and mechanical properties of $\mathrm{CoCrFeNiTiAl}_{\mathrm{x}}$ high-entropy alloys. Mater. Sci. Eng. A 2009, 508, 214.

[50] M. H. Chuang, M. H. Tsai, W. R. Wang, S. J. Lin, J. W. Yeh, Microstructure and wear behavior of $\mathrm{Al}_{x} \mathrm{Co}_{1.5} \mathrm{CrFeNi}_{1.5} \mathrm{Ti}_{y}$ high-entropy alloys. Acta Mater. 2011, 59, 6308.

[51] J. W. Qiao, Microstructural characteristics and mechanical behaviours of AlCoCrFeNi high-entropy alloys at ambient and cryogenic temperatures. Mater. Sci. Forum 2011, 688, 419.

[52] Y. J. Zhou, Y. Zhang, X. F. Wang, Y. L. Wang, G. L. Chen, Effect of component substitution on the microstructure and mechanical properties of $\mathrm{MCoCrFeNiTi}_{x},(\mathrm{M}=\mathrm{Cu}, \mathrm{Al})$ solid-solution alloys. Rare Met. 2008, 27, 627.

[53] Y. J. Zhou, Y. Zhang, F. J. Wang, Y. L. Wang, G. L. Chen, Effect of $\mathrm{Cu}$ addition on the microstructure and mechanical properties of AlCoCrFeNiTi ${ }_{0.5}$ solid-solution alloy. J. Alloys Compd. 2008, 466, 201.

[54] F. J. Wang, Y. Zhang, Effect of Co addition on crystal structure and mechanical properties of $\mathrm{Ti}_{0.5} \mathrm{CrFeNiAlCo}$ high entropy alloy. Mater. Sci. Eng. A 2008, 496, 214.

[55] Y. J. Hsu, W. C. Chiang, J. K. Wu, Corrosion behavior of FeCoNi$\mathrm{CrCu}_{\mathrm{x}}$ high-entropy alloys in $3.5 \%$ sodium chloride solution. Mater. Chem. Phys. 2005, 92, 112.

[56] C. M. Lin, H. L. Tsai, Effect of annealing treatment on microstructure and properties of high-entropy $\mathrm{FeCoNiCrCu}_{0.5}$ alloy. Mater. Chem. Phys. 2011, 128, 50. 
[57] F. J. Wang, Y. Zhang, G. L. Chen, Atomic packing efficiency and phase transition in a high entropy alloy. J. Alloys Compd. 2009, 478, 321.

[58] Y. Zhang, X. F. Wang, G. Chen, Y. Qiao, Effect of Ti on the microstructure and properties of $\mathrm{CoCrCuFeNiTi}_{\mathrm{x}}$ high-entropy alloys. Ann. Chim. Sci. Mat. 2006, 31, 699.

[59] M. R. Chen, S. J. Lin, J. W. Yeh, S. K. Chen, Y. S. Huang, C. P. Tu, Microstructure and properties of $\mathrm{Al}_{0.5} \mathrm{CoCrCuFeNiTi}_{\mathrm{x}}(\mathrm{x}=0-2.0)$ high-entropy alloys. Mater. Trans. 2006, 47, 1395.

[60] B. S. Li, Y. R. Wang, M. X. Ren, C. Yang, H. Z. Fu, Effects of Mn, $\mathrm{Ti}$ and $\mathrm{V}$ on the microstructure and properties of AlCrFeCoNiCu high entropy alloy. Mater. Sci. Eng. A 2008, 498, 482.

[61] Y. J. Zhou, Y. Zhang, Y. L. Wang, G. L. Chen, Microstructure and compressive properties of multicomponent $\mathrm{Al}_{\mathrm{x}}(\mathrm{TiVCrMnFeCoNiCu})_{100-x}$ high-entropy alloys. Mater. Sci. Eng. A 2007, 454/455, 260.

[62] B. Cantor, I. T. H. Chang, P. Knight, A. J. B. Vincent, Microstructural development in equiatomic multicomponent alloys. Mater. Sci. Eng. A 2004, 375-377, 213.

[63] Y. Dong, Y. Lu, J. Kong, J. Zhang, T. Li, Microstructure and mechanical properties of multi-component $\mathrm{AlCrFeNiMo}_{x}$ highentropy alloys. J. Alloys Compd. 2013, 573, 96.

[64] B. Ren, Z. X. Liu, D. M. Li, L. Shi, B. Cai, M. X. Wang, Effect of elemental interaction on microstructure of $\mathrm{CuCrFeNiMn}$ highentropy alloy system. J. Alloys Compd. 2010, 493, 148.

[65] C. P. Lee, C. C. Chang, Y. Y. Chen, J. W. Yeh, H. C. Shih, Effect of the aluminium content of $\mathrm{Al}_{\mathrm{x}} \mathrm{CrFe}_{1.5} \mathrm{MnNi}_{0.5}$ high-entropy alloys on. the corrosion behavior in aqueous environments. Corros. Sci. 2008, 50, 2053.

[66] S. T. Chen, W. Y. Tang, Y. F. Kuo, S. Y. Chen, C. H. Tsau, T. T. Shun, J. W. Yeh, Microstructure and properties of age-hardenable $\mathrm{Al}_{\mathrm{x}} \mathrm{CrFe}_{1.5} \mathrm{MnNi}_{0.5}$ alloys. Mater. Sci. Eng. A 2010, 527, 5818.

[67] H. Y. Chen, C. W. Tsai, C. C. Tung, J. W. Yeh, T. T. Shun, C. C. Yang, $\mathrm{S}$. K. Chen, Effect of the substitution of $\mathrm{Co}$ by $\mathrm{Mn}$ in Al-Cr-Cu-FeCo-Ni high-entropy alloys. Ann. Chim. Sci. Mat. 2006, 31, 685.

[68] Y. F. Kao, S. K. Chen, J. H. Sheu, J. T. Lin, W. E. Lin, J. W. Yeh, S. J. Lin, T. H. Liou, C. W. Wang, Hydrogen storage properties of multi-principal-component $\mathrm{CoFeMnTi} \mathrm{V}_{\mathrm{y}} \mathrm{Zr}_{\mathrm{z}}$ alloys. Int. J. Hydrogen Energy 2010, 35, 9046.

[69] L. Liu, J. B. Zhu, C. Zhang, J. C. Li, Q. Jiang, Microstructure and the properties of FeCoCuNiSn $n_{x}$ high entropy alloys. Mater. Sci. Eng. A 2012, 548, 64.

[70] Y. X. Zhuang, W. J. Liu, P. F. Xing, F. Wang, J. C. He, Effect of Co element on microstructure and mechanical properties of FeCo NiCuAl alloys. Acta Metall. Sin. 2012, 25, 124.

[71] Y. Y. Du, Y. P. Lu, T. J. Li, T. M. Wang, G. L. Zhang, Effect of aluminium content of $\mathrm{Al}_{\mathrm{x}} \mathrm{CrFe}_{1.5} \mathrm{Ni}_{0.5}$ multiprincipal alloys on microstructure and alloy hardness. Mater. Res. Innovations 2011, 15, 107

[72] C. Ng, S. Guo, J. Luan, Q. Wang, J. Lu, S. Shi, C. T. Liu, Phase stability and tensile properties of Co-free $\mathrm{Al}_{0.5} \mathrm{CrCuFeNi}_{2}$ highentropy alloys. J. Alloys Compd. 2014, 584, 530.

[73] S. Guo, C. Ng, J. Lu, C. T. Liu, Effect of valence electron concentration on stability of fcc or bcc phase in high entropy alloys. J. Appl. Phys. 2011, 109, 103505.

[74] J. H. Pi, Y. Pan, H. Zhang, L. Zhang, Microstructure and properties of $\mathrm{AlCrFeCuNi}_{\mathrm{x}}(0.6 \leq \mathrm{x} \leq 1.4)$ high-entropy alloys. Mater. Sci. Eng. A 2012, 534, 228.

[75] C. Li, J. C. Li, M. Zhao, Q. Jiang, Effect of alloying elements on microstructure and properties of multiprincipal elements highentropy alloys. J. Alloys Compd. 2009, 475, 752.
[76] J. H. Pi, Y. Pan, L. Zhang, H. Zhang, Microstructure and property of AlTiCrFeNiCu high-entropy alloy. J. Alloys Compd. 2011, 509, 5641.

[77] U. S. Hsu, U. D. Hung, J. W. Yeh, S. K. Chen, Y. S. Huang, C. C.Yang, Alloying behavior of iron, gold and silver in $\mathrm{AlCoCr}-$ CuNi-based equimolar high-entropy alloys. Mater. Sci. Eng. A 2007, 460, 403.

[78] Z. H. Hu, Y. Z. Zhan, G. H. Zhang, J. She, C. H. Li, Effect of rare earth $\mathrm{Y}$ addition on the microstructure and mechanical properties of high entropy AlCoCrCuNiTi alloys. Mater. Des. 2010, 31, 1599.

[79] O. N. Senkov, G. B. Wilks, D. B. Miracle, C. P. Chuang, P. K. Liaw, Refractory high-entropy alloys. Intermetallics 2010, 18, 1758.

[80] O. N. Senkov, G. B. Wilks, J. M. Scott, D. B. Miracle, Mechanical properties of $\mathrm{Nb}_{25} \mathrm{Mo}_{25} \mathrm{Ta}_{25} \mathrm{~W}_{25}$ and $\mathrm{V}_{20} \mathrm{Nb}_{20} \mathrm{Mo}_{20} \mathrm{Ta}_{20} \mathrm{~W}_{20}$ refractory high entropy alloys. Intermetallics 2011, 19, 698.

[81] O. N. Senkov, J. M. Scott, S. V. Senkova, D. B. Miracle, C. F. Woodward, Microstructure and room temperature properties of a high-entropy TaNbHfZrTi alloy. J. Alloys Compd. 2011, 509, 6043.

[82] O. N. Senkov, J. M. Scott, S. V. Senkova, F. Meisenkothen, D. B. Miracle, C. F. Woodward, Microstructure and elevated temperature properties of a refractory TaNbHfZrTi alloy. J. Mater. Sci. 2012, 47, 4062.

[83] Y. Zhang, X. Yang, P. K. Liaw, Alloy design and properties optimization of high-entropy alloys. J. Miner. Met. Mater. Soc. 2012, 64, 830 .

[84] O. N.,Senkov, C. F. Woodward, Microstructure and properties of a refractory $\mathrm{NbCrMo}_{0.5} \mathrm{Ta}_{0.5} \mathrm{TiZr}$ alloy. Mater. Sci. Eng. A 2011, $529,311$.

[85] O. N. Senkov, S. V. Senkova, D. M. Dimiduk, C. Woodward, D. B. Miracle, Oxidation behavior of a refractory $\mathrm{NbCrMo}_{0.5} \mathrm{Ta}_{0.5} \mathrm{TiZr}$ alloy. J. Mater. Sci. 2012, 47, 6522.

[86] C. M. Liu, H. M. Wang, S. Q. Zhang, H. B.Tang, A. L. Zhang, Microstructure and oxidation behavior of new refractory high entropy alloys. J. Alloys Compd. 2014, 583, 162.

[87] S. G. Ma, S. F. Zhang, M. C. Gao, P. K. Liaw, Y. Zhang, A successful synthesis of the $\mathrm{CoCrFeNiAl}_{0.3}$ single-crystal, high-entropy alloy by bridgman solidification. J. Miner. Met. Mater. Soc. 2013, 65, 1751.

[88] M. J. Yao, K. G. Pradeep, C. C. Tasan, D. Raabe, A novel, single phase, non-equiatomic FeMnNiCoCr high-entropy alloy with exceptional phase stability and tensile ductility. Scr. Mater. 2014, 72-73, 5.

[89] J. Y. He, W. H. Liu, H. Wang, Y. Wu, X. J. Liu, T. G. Nieh, Z. P. Lu, Effects of Al addition on structural evolution and tensile properties of the FeCoNiCrMn high-entropy alloy system. Acta Mater. 2014, 62, 105.

[90] M. Feuerbacher, M. Heidelmann, C. Thomas, Plasticity of Zr-Nb-Ti-Ta-Hf high-entropy alloys. http://arxiv.org/ftp/arxiv/ papers/1401/1401.3997.pdf. 2014.

[91] T. B. Massalski, P. R. Subramanian, H. Okamoto, L. Kacprzak, Binary Alloy Phase Diagrams, 2nd ed., Vol. 1, 2, and 3, ASM International, Materials Park, OH, 1990.

[92] Z. Tang, M. C. Gao, H. Diao, T. Yang, J. Liu, T. Zuo, Y. Zhang, Z. Lu, Y. Cheng, Y. Zhang, K. A. Dahmen, P. K. Liaw, T. Egami, Aluminum alloying effects on lattice types, microstructures, and mechanical behavior of high-entropy alloys systems. J. Miner. Met. Mater. Soc. 2013, 65, 1848.

[93] H. Bei, Multi-component solid solution alloys having high mixing entropy, Patent US2013/0108502A1. 
[94] M. F. del Grosso, G. Bozzolo, H. O. Mosca, Determination of the transition to the high entropy regime for alloys of refractory elements. J. Alloys Compd. 2012, 534, 25.

[95] C. H. Zhang, M. H. Lin, B. Wu, G. X. Ye, L. K. Zhang, T. Chen, W. J. Zhang, Z. H. Zheng, Q. Li, Y. Q. Shao, B. Y. Zhou, C. Wang, Explore the possibility of forming fcc high entropy alloys in equal-atomic systems CoFeMnNi M and CoFeMnNiSm M. J. Shanghai Jiaotong Univ. (Sci.) 2011, 16, 173.

[96] L. S. Darken, R. W. Gurry, Physical Chemistry of Metals, McGraw-Hill, New York, 1953.

[97] K. A. Gschneidner, M. Verkade, Electronic and crystal structures, size (ECS2) model for predicting binary solid solutions. Prog. Mater. Sci. 2004, 49, 411.

[98] F. R. Boer, D. G. Perrifor, Cohesion in Metals, Elsevier Science Publishers B.V., Netherlands, pp.1-758, 1988.

[99] W. L. Bragg, The crystalline structure of copper. Philos. Mag. 1914, 28, 355.

[100] H. Hartmann, F. Ebert, O. Bretschneider, electrolysis in phosphate fussions I electrolytical extraction of alpha and beta-Wolframe. Z. Anorg. Allg. Chem. 1931, 198, 116.

[101] W. P. Davey, F. G. Wick, Crystal structures of $\mathrm{CsCl}$ and TICl. Phys. Rev. 1921, 17, 403.

[102] J. K. Burdett, S. Lee, T. J. McLarnan, The coloring problem. J. Am. Chem. Soc. 1985, 107, 3083.

[103] M. Widom, W. P. Huhn, S. Maiti, W. Steurer, Hybrid monte carlo/molecular dynamics simulation of a refractory metal high entropy alloy. Metall Mat. Trans. A 2014, 45, 196.

[104] M. F. del Grosso, G. Bozzolo, H. O. Mosca, Modeling of high entropy alloys of refractory elements. Phys. B 2012, 407, 3285.

[105] F. Y. Tian, L. K. Varga, N. X. Chen, L. Delczeg, L. Vitos, Ab initio investigation of high-entropy alloys of $3 \mathrm{~d}$ elements. Phys. Rev. B 2013, 87, 075144.
[106] J. W. Yeh, Y. L. Chen, S. J. Lin, S. K. Chen, High-entropy alloys - a new era of exploitation. Mater. Sci. Forum 2007, $560,1$.

[107] D.A. Wigley, Mechanical Properties of Materials at Low Temperatures, Plenum Press, New York, 1971.

[108] K.-Y. Tsai, M.-H. Tsai, J.-W. Yeh, Sluggish diffusion in Co-Cr-FeMn-Ni high-entropy alloys. Acta Mater. 2013, 61, 4887.

[109] A. J. Zaddach, C. Niu, C. C. Koch, D. L. Irving, Mechanical properties and stacking fault energies of NiFeCrCoMn highentropy alloy. JOM 2013, 65, 1780.

[110] W. H. Liu, Y. Wu, J. Y. He, T. G. Nieh, Z. P. Lu, Grain growth and the Hall-Petch relationship in a high-entropy FeCrNiCoMn alloy. Scr. Mater. 2013, 68, 526.

[111] A. Gali, E. P. George, Tensile properties of high- and mediumentropy alloys. Intermetallics 2013, 39, 74.

[112] Z. S. Basinski, R. A. Foxall, R. Pascual, stress equivalence of solution hardening. Scripta Metallurgica 1972, 6, 807.

[113] H. Traub, H. Neuhauser, S. Ch, Investigations of the yield region of concentrated $\mathrm{Cu}-\mathrm{Ge}$ and $\mathrm{Cu}-\mathrm{Zn}$ single crystals-I. Critical resolved shear stress, slip line formation and the true strain rate. Acta Metall. 1977, 25, 437.

[114] T. Wille, C. Schwink, Precision measurements of critical resolved shear sress in CuMn alloys. Acta Metall. 1986, 34 , 1059.

[115] Y. Zou, S. Maiti, W. Steurer, R. Spolenak, Size-dependent plasticity in an Nb25Mo25Ta25W25 refractory high-entropy alloy. Acta Mater. 2014, 65, 85.

[116] O. Soriano-Vargas, E. O. Avila-Davila, V. M. Lopez-Hirata, H. J. Dorantes-Rosales, J. L. Gonzalez-Velazquez, Spinodal decomposition in an $\mathrm{Fe}-32$ at\% $\mathrm{Cr}$ alloy during isothermal aging. Mater. Trans. 2009, 50, 1753.

[117] A. L. Greer, Confusion by design. Nature 1993, 366, 303. 